\title{
DETERMINAN KEJADIAN STUNTING DAN UNDERWEIGHT PADA BALITA SUKU ANAK DALAM DI DESA NYOGAN KABUPATEN MUARO JAMBI TAHUN 2019
}

\author{
Determinants of Stunting and Underweight of underfive children of Suku Anak Dalam \\ in Nyogan Village Muaro Jambi, 2019
}

\author{
Abdul Haris ${ }^{1}$, Adelina Fitri ${ }^{1}$, Ummi Kalsum ${ }^{1}$ \\ ${ }^{1}$ Program Studi Kesehatan Masyarakat, Fakultas Kesehatan Masyarakat Universitas Jambi
}

\begin{abstract}
ABSTRAK
Stunting dan Underweight berkaitan dengan peningkatan risiko kesakitan dan penyebab kematian di dunia. Berbagai faktor menjadi penyebab terjadinya, salah satunya adalah faktor kemiskinan yang saat ini dialami suku anak dalam (SAD). Tujuan penelitian untuk mengetahui proporsi dan determinan stunting dan underweight pada balita suku anak dalam di Desa Nyogan Kabupaten Muaro Jambi. Desain penelitian adalah cross sectional. Lokasi di Desa Nyogan Kab. Muaro Jambi menggunakan total populasi, melibatkan 45 balita suku anak dalam berusia 12-59 bulan. Variabel yang diteliti adalah durasi menyusui, riwayat penyakit infeksi, status imunisasi dasar lengkap, sanitasi lingkungan, besar keluarga dan ketersediaan pangan tingkat rumah tangga yang diperoleh dengan wawancara dan pengukuran status gizi dengan indikator $\mathrm{BB} / \mathrm{U}$ dan $\mathrm{TB} / \mathrm{U}$. Analisis data menggunakan uji Chi-Square pada $\alpha=0,05$. Ditemukan proporsi stunting $42,2 \%$ dan underweight $17,8 \%$. Hasil penelitian menunjukkan ada hubungan durasi menyusui dengan kejadian stunting $(P=0,011 ; P R=2,92 ; 95 \% C I$ $=1,26-6,76)$, dan besar keluarga dengan kejadian underweight $(P=0,033 ; P R=4,80 ; 95 \% C I=$ 1,61-14,25). Determinan yang tidak berhubungan dengan kejadian stunting dan underweight adalah riwayat penyakit infeksi, status imunisasi, sanitasi dan ketersediaan pangan. Sebaiknya orang tua balita SAD tetap memberikan ASI hingga balita berusia 2 tahun untuk mencegah stunting dan keluarga Suku Anak Dalam membatasi jumlah anak dengan Keluarga Berencana untuk mencegah underweight.
\end{abstract}

Kata Kunci : Stunting, Underweight, SAD, balita.

\begin{abstract}
Stunting and Underweight are associated with an increased risk of morbidity and causes of death in the world. Various factors cause of stunting and underweight, e.g. the poverty that currently experienced by SAD's children. This study aim was to determine the proportion and determinants of stunting and underweight in SAD's under five children in Nyogan Village, Muaro Jambi District. The study design was cross sectional. Location in Nyogan Village Muaro Jambi District uses a total population, involving 45 children $<12-59$ months. The variables of this study were breastfeeding duration, infectious diseases history, complete basic immunization status, sanitation, family size and household food availability obtained by interviews and measurements of nutritional status by Weight/Age and Height/Age. Data analysis used Chi-Square at $\alpha=0.05$. The proportion of stunting was $42.2 \%$ and underweight was $17.8 \%$. The results showed a relationship between breastfeeding duration with the occurence of stunting $(\mathrm{P}=0.011 ; \mathrm{PR}=2.92 ; 95 \% \mathrm{CI}=1.26-6.76)$, and family size related to underweight $(\mathrm{P}=0.033 ; \mathrm{PR}=4.8095 \% \mathrm{CI}=1.61-14.25)$. Determinants which have no relationship to stunting and underweight were infectious diseases history, immunization status, sanitation and food availability. There was a relationship between breastfeeding duration to stunting and family size to underweight. Parents of SAD's children should continue breastfeeding until 2 years-old to prevent stunting and families of underfive children consider to limit the number of children by use the contraceptive or participate to Family Planning program to prevent underweight.
\end{abstract}

Keywords : Stunting, Underweight, SAD, underfive.

Korespondensi : Ummi Kalsum

Email : ummi2103@unja.ac.id 


\section{PENDAHULUAN}

Stunting dan underweight menjadi masalah utama pada gizi kurang, yang akan membuat anak mengalami gangguan kesehatan, baik jangka pendek maupun jangka panjang. Stunting pada balita dapat menghambat perkembangan fisik dan mental anak. Stunting meningkatkan risiko kesakitan dan kematian serta terhambatnya pertumbuhan kemampuan motorik dan mental. ${ }^{1}$ Lebih dari 2 juta kematian anak dibawah umur 5 tahun di dunia berhubungan langsung dengan gizi buruk terutama karena pendek dan kurus. Satu dari tiga anak berusia balita atau sekitar 178 juta anak yang hidup di negara miskin dan berkembang mengalami kekerdilan (stunted), 111,6 juta hidup di Asia dan 56,9 juta hidup di Afrika. Sedangkan menurut data UNICEF, ada sekitar 195 juta anak yang hidup di negara miskin dan berkembang mengalami stunted. ${ }^{2}$

Masalah gizi lainnya yang terjadi pada anak adalah underweight. Underweight atau biasa disebut gizi kurang atau gizi buruk dinyatakan sebagai penyebab kematian 3,5 juta anak balita di dunia. WHO (2002) memperkirakan 54\% penyebab kematian bayi dan balita di dasari keadaan gizi buruk. Resiko meninggal dari anak yang bergizi buruk 13 kali lebih besar dibandingkan anak normal. Data WHO menunjukkan 49\% dari 10,4 juta kematian balita di Negara berkembang berhubungan dengan gizi buruk. Tercatat sekitar 30\% balita Afrika, 20\% di Amerika Latin dan $50 \%$ balita Asia menderita gizi buruk salah satunya adalah Indonesia. ${ }^{3}$

Di Indonesia, penurunan stunting menjadi prioritas dalam Rencana Pembangunan Jangka Menengah Nasional (RPJMN) 2015-2019. Hasil Riskesdas, prevalensi balita pendek dan sangat pendek tahun 2018 sebesar 30,8\% dan prevalensi gizi kurang dan gizi buruk $17,7 \%$. Angka ini masih harus diturunkan sesuai dengan target Sustainable Development Goals. Data dari Global Nutrition Report tahun 2014 menunjukkan Indonesia termasuk dalam 17 negara di antara 117 negara yang mempunyai tiga masalah gizi yaitu stunting, wasting dan overweight pada balita. ${ }^{4}$

Provinsi Jambi termasuk salah satu Provinsi di Indonesia yang tidak terlepas dari permasalahan gizi balita. Hasil Riskesdas 2018, prevalensi stunting di Provinsi Jambi 20,68\%, sedangkan prevalensi underweight sebesar $15,74 \%$. Meskipun secara kuantitas permasalahan gizi di Provinsi Jambi relatif turun dari tahun sebelumnya, namun secara kualitas sebenarnya tidak ada perubahan pada permasalahan gizinya, termasuk pula di salah satu Kabupaten di Provinsi Jambi yaitu Kabupaten Muaro Jambi dengan prevalensi stunting sebesar $16,1 \%$ dan underweight sebesar $11,69 \%{ }^{4}$

Kasus gizi buruk di Jambi banyak disebabkan oleh kemiskinan dan rendahnya pengetahuan tentang gizi. Komunitas yang mengalami kemiskinan diantaranya adalah Suku Anak Dalam. Kemiskinan semakin menjerat SAD karena berkurangnya lahan dan sumber kehidupan mereka yang sangat bergantung pada berburu dan meramu hasil hutan yang semakin hari semakin sempit karena adanya perubahan fungsi lahan. ${ }^{5}$

Komunitas SAD di Jambi masih cukup banyak. Jumlah SAD di Provinsi Jambi sampai dengan tahun 2010 tercatat sebanyak $6.773 \mathrm{KK}$ atau 28.883 jiwa yang tersebar di 8 Kabupaten yaitu Kabupaten Muaro Jambi, Batanghari, Tebo, Sarolangun, Merangin, Bungo, Tanjung Jabung Barat dan Tanjung Jabung Timur. Ada beberapa kelompok yang sudah dibina 
dan dirumahkan oleh pemerintah, diantaranya di Desa Nyogan Kabupaten Muaro Jambi sejak tahun $2004 .^{6}$ Perubahan pola kehidupan dari nomaden menjadi menetap mengakibatkan terjadinya perubahan mata pencaharian, gaya hidup dan pola makan sehari-hari dari komunitas SAD ini.

Hasil penelitian Kalsum menemukan proporsi Stunting pada balita orang rimba di Desa Sungai Terap dan Hajran Kabupaten Batanghari adalah $21,7 \%$ dan $24 \%$ balita mengalami underweight. Faktor yang berperan terhadap status gizi balita SAD tersebut adalah pola konsumsi dan pola perkawinan, sanitasi lingkungan serta tingkat pengetahuan yang relatif rendah. ${ }^{7}$

Banyak faktor yang mempengaruhi status gizi balita baik stunting dan underweight diantaranya asupan makanan, penyakit infeksi, sanitasi, durasi menyusui, status imunisasi, besar keluarga, ketersediaan pangan tingkat rumah tangga, pola asuh dan tingkat sosial ekonomi keluarga. $^{8-17}$

Faktor kemiskinan, pendidikan dan pengetahuan yang rendah serta sanitasi lingkungan yang kurang baik pada komunitas SAD membuat mereka rentan terhadap berbagai jenis penyakit, yang berdampak pula pada status gizinya. Tujuan penelitian ini adalah untuk mengetahui proporsi dan menganalisis determinan stunting dan underweight pada balita suku anak dalam di Desa Nyogan Kabupaten Muaro Jambi.

\section{METODE}

Disain penelitian ini adalah cross sectional. Penelitian dilakukan di Desa Nyogan Kecamatan Mestong Kabupaten Muaro Jambi, yang dilaksanakan pengumpulan datanya pada bulan April
2019. Populasi adalah anak usia 12-59 bulan di Desa Nyogan Kecamatan Mestong Kabupaten Muaro Jambi berjumlah 43 orang. Responden adalah ibu dari anak umur 12-59 bulan atau orang yang sehari-hari mengasuhnya.

Jumlah sampel dihitung menggunakan rumus uji hipotesis untuk beda proporsi dari Lemeshow dan Lwanga. ${ }^{18}$ Jumlah sampel minimal yang dibutuhkan sebanyak 65 balita, namun peneliti hanya memperoleh total balita yang ada sebanyak 45 orang (total sampling). Kriteria inklusi pada penelitian ini adalah anak berusia 12-59 bulan dari SAD atau keturunan SAD satu tingkat (memiliki ayah atau ibu SAD); mendapat persetujuan dari kepala keluarga (pengasuhnya) dan bersedia berpartisipasi dalam penelitian dengan menandatangani informed consent telah tinggal di wilayah tersebut minimal selama 6 bulan serta tidak sedang menderita sakit berat/kronis.

Data dikumpulkan dengan wawancara menggunakan kuisioner terstruktur terhadap variabel durasi menyusui, riwayat penyakit infeksi, status imunisasi, sanitasi lingkungan, besar keluarga dan ketersediaan pangan. Pengukuran tinggi badan dan berat badan balita dilakukan oleh Peneliti dan pembantu peneliti dengan mengukur berat badan menggunakan timbangan digital (ketelitian $0,1 \quad \mathrm{~kg}$ ) dan stadiometer portable untuk mengukur tinggi badan balita dengan ketelitian hingga $0,1 \mathrm{~cm}$. Stunting dan underweight dihitung menggunakan indikator $\mathrm{BB} / \mathrm{U}$ dan $\mathrm{TB} / \mathrm{U}$ dengan bantuan software WHO Anthro untuk mendapatkan nilai Z-score, sehingga dapat dikelompokkan menjadi stunting atau underweight jika $<-3$ standar deviasi hingga $<-2$ standar deviasi; dan normal jika $>=-2$ standar deviasi. Analisis data 
menggunakan uji Chi-Square dengan alternatif Uji ExactFisher dan Continuity Correction pada tingkat kepercayaan $95 \%$.

\section{HASIL PENELITIAN}

Karakteristik responden rata-rata berusia 30 tahun dengan usia minimal 17 tahun dan maksimal 44 tahun. Sedangkan jumlah anggota rumah tangga responden rata-rata empat orang dengan minimal tiga orang dan maksimal delapan orang Proporsi balita stunting sebanyak 42,2\% dan balita underweight sebanyak 17,8\%.

Mayoritas responden berusia lebih atau sama dengan 20 tahun dengan status kawin dan jenis kelamin hampir seluruhnya perempuan. Responden kebanyakan berpendidikan rendah, mayoritas pekerjaan ayah tidak tetap dan ibu tidak bekerja dengan jumlah anggota keluarga kebanyakan kurang atau sama dengan lima. Balita laki-laki dan perempuan hampir sama proporsinya dan mayoritas rumah tangga berpendapatan rendah (tabel 1).

Penelitian ini menemukan bahwa rata-rata durasi menyusui adalah 22,35 bulan, rata-rata nilai sanitasi 23,64 , ratarata jumlah anggota rumah tangga 4,02 orang dan rata-rata skor ketersediaan pangan adalah 335,11 (tabel 2).

Tabel 1. Karakteristik Sosiodemografi Responden di Desa Nyogan Kab. Muaro Jambi

\begin{tabular}{|c|c|c|}
\hline Variabel & Jumlah (n) & Persentase $(\%)$ \\
\hline \multicolumn{3}{|l|}{ Usia } \\
\hline$<20$ tahun & 3 & 6,7 \\
\hline$\geq 20$ tahun & 42 & 93,3 \\
\hline \multicolumn{3}{|l|}{ Status Perkawinan } \\
\hline Kawin & 38 & 84,4 \\
\hline Tidak Kawin & 7 & 15,6 \\
\hline \multicolumn{3}{|l|}{ Jenis Kelamin } \\
\hline Laki-laki & 1 & 2,2 \\
\hline Perempuan & 44 & 97,8 \\
\hline \multicolumn{3}{|l|}{ Pendidikan } \\
\hline Tinggi & 11 & 24,4 \\
\hline Rendah & 34 & 75,6 \\
\hline \multicolumn{3}{|l|}{ Pekerjaan Ayah } \\
\hline Tetap & 3 & 6,7 \\
\hline Tidak Tetap & 37 & 82,5 \\
\hline \multicolumn{3}{|l|}{ Pekerjaan Ibu } \\
\hline Bekerja & 12 & 26,7 \\
\hline Tidak Bekerja & 33 & 73,3 \\
\hline \multicolumn{3}{|l|}{ Besar Keluarga } \\
\hline Kecil & 40 & 88,9 \\
\hline Besar & 5 & 11,1 \\
\hline \multicolumn{3}{|l|}{ Jenis Kelamin Balita } \\
\hline Laki-laki & 25 & 55,6 \\
\hline Perempuan & 20 & 44,4 \\
\hline \multicolumn{3}{|c|}{ Pendapatan Rumah Tangga } \\
\hline Tinggi & 12 & 26,7 \\
\hline Rendah & 33 & 73,3 \\
\hline
\end{tabular}

Sumber : Data Primer Terolah, 2019 
Tabel 2. Simpulan Data menurut Durasi Menyusui, Riwayat Penyakit Infeksi, Status Imunisasi dan Sanitasi Lingkungan

\begin{tabular}{lcccc}
\hline \multicolumn{1}{c}{ Variabel } & Min-Max & Mean (95\% CI) & SD & Median \\
\hline $\begin{array}{l}\text { Durasi Menyusui } \\
\text { Lama anak diberi ASI (bulan) }\end{array}$ & $12-36$ & $22,35(20,22-24,49)$ & 6,119 & 24 \\
$\begin{array}{l}\text { Sanitasi Lingkungan } \\
\begin{array}{l}\text { Skor Sanitasi Lingkungan } \\
\text { Besar Keluarga }\end{array}\end{array}$ & $8-33$ & $23,64(22,06-25,23)$ & 5,288 & 23 \\
$\begin{array}{l}\text { Jumlah ART (orang) } \\
\text { Ketersediaan Pangan }\end{array}$ & $3-8$ & $4,02(3,67-4,38)$ & 1,177 & 4 \\
Skor Ketersediaan Pangan (kal) & $216,67-629,05$ & $335,11(308,17-362,04)$ & 89,65 & 309,52 \\
\hline
\end{tabular}

Sumber : Data Primer Terolah, 2019

Durasi menyusui balita hampir sama proporsinya antara yang kurang dari 24 bulan dan lebih atau sama dengan 24 bulan. Kebanyakan balita tidak memiliki riwayat penyakit infeksi, namun sudah mendapatkan imunisasi dasar lengkap
$(57,8 \%)$. Sanitasi lingkungan sedikit lebih banyak pada kondisi kurang, besar keluarga mayoritas memiliki jumlah anggota $<5$ orang dan $64,4 \%$ ketersediaan pangan pada kategori cukup baik (tabel 3).

Tabel 3. Distribusi menurut Durasi Menyusui, Riwayat Penyakit Infeksi, Status Imunisasi, Sanitasi Lingkungan, besar keluarga dan ketersediaan pangan

\begin{tabular}{lcc}
\hline \multicolumn{1}{c}{ Variabel } & Jumlah (n) & Persentase (\%) \\
\hline Durasi Menyusui & & \\
$\geq 24$ bulan & 23 & 51,1 \\
$<24$ bulan & 22 & 48,9 \\
\hline Riwayat Penyakit Infeksi & & \\
$\quad$ Ada & 10 & 22,2 \\
$\quad$ Tidak Ada & 35 & 77,8 \\
\hline Status Imunisasi & & \\
$\quad$ Lengkap & 26 & 57,8 \\
$\quad$ Tidak Lengkap & 19 & 42,2 \\
\hline Sanitasi Lingkungan & & \\
$\quad$ Baik & 22 & 48,9 \\
$\quad$ Kurang Baik & 23 & 51,1 \\
\hline Besar Keluarga & & \\
$\quad$ Kecil & 40 & 88,9 \\
Besar & 5 & 11,1 \\
\hline Ketersediaan Pangan & & \\
Cukup & 29 & 64,4 \\
Kurang & 16 & 35,6 \\
\hline
\end{tabular}

Sumber : Data Primer Terolah, 2019

Terdapat hubungan antara durasi menyusui dengan kejadian stunting, dimana balita yang mendapatkan ASI kurang dari 24 bulan memiliki resiko 2,92 kali mengalami stunting dibandingkan balita yang mendapat ASI >= 24 bulan. Namun penelitian ini belum dapat membuktikan hubungan antara riwayat penyakit infeksi, status imunisasi, sanitasi lingkungan, besar keluarga dan ketersediaan pangan tingkat rumah tangga dengan kejadian stunting pada balita SAD di Desa Nyogan. Ditemukan hubungan yang signifikan antara besar keluarga 
dengan kejadian underweight, dimana balita dengan anggota rumah tangga yang besar beresiko 4,8 kali mengalami underweight dibandingkan keluarga dengan anggota rumah tangga yang kecil. Hasil penelitian ini belum dapat membuktikan adanya hubungan antara durasi menyusui, riwayat penyakit infeksi, status imunisasi, sanitasi lingkungan dan ketersediaan pangan di tingkat rumah tangga dengan kejadian underweight (tabel 4).

\section{PEMBAHASAN}

Penelitian ini menemukan bahwa proporsi stunting pada balita suku anak dalam di desa Nyogan Kabupaten Muaro Jambi lebih tinggi dibandingkan proporsi stunting pada balita di Kabupaten Muaro Jambi tahun 2017 yaitu hanya 16,1\% dan lebih tinggi daripada proporsi stunting pada balita secara nasional tahun 2018 yaitu $30,8 \% .{ }^{19}$ Sedangkan proporsi balita underweight pada suku anak dalam di Desa Nyogan Kabupaten Muaro Jambi relatif sama dengan proporsi underweight secara nasional pada tahun 2018 yakni $17,7 \% .^{4}$

Proporsi underweight pada balita SAD di Desa Nyogan Kabupaten Muaro Jambi lebih rendah daripada proporsi underweight pada balita di Desa Sungai Terap dan Hajran Kabupaten Batanghari pada tahun 2018 yang menunjukkan hasil $24 \%$ balita mengalami underweight $(12 \%$ pada gizi buruk dan $12 \%$ pada gizi kurang). ${ }^{7}$ Penelitian ini menemukan bahwa penyebab underweight karena kemiskinan dan rendahnya pengetahuan ibu mengenai makanan bergizi. Kemiskinan secara tidak langsung menyebabkan makanan bergizi untuk anak-anak berkurang, sementara kurangnya pengetahuan ibu mengenai makanan bergizi membuat mereka kurang memperhatikan kualitas makanan yang diberikan kepada anak-anak khususnya balita. $^{7}$ Proporsi yang lebih tinggi ditemukan oleh Fitri dkk yang melakukan penelitian pada balita SAD di wilayah kerja Puskesmas Pematang Kabau Kecamatan Air Hitam Kabupaten Sarolangun Jambi pada tahun 2017 yang menemukan bahwa $30 \%$ balita SAD mengalami underweight. ${ }^{20}$

Balita merupakan kelompok rentan, khususnya di negara berkembang seperti Indonesia, balita merupakan golongan yang paling rawan terhadap gizi karena anak-anak biasanya menderita bermacammacam infeksi serta berada dalam status gizi rendah. Tingginya proporsi stunting dan underweight pada balita SAD disebabkan oleh beberapa faktor baik langsung maupun tidak langsung. Hasil penelitian ini membuktikan bahwa ada hubungan antara durasi menyusui dengan kejadian stunting, namun riwayat penyakit infeksi, status imunisasi, sanitasi, besar keluarga dan ketersediaan pangan belum terbukti signifikan terhadap kejadian stunting pada balita suku anak dalam di Desa Nyogan.

Hal penelitian ini sejalan dengan hasil penelitian Susilowati et al (2010) yang menunjukkan ada hubungan signifikan antara durasi pemberian ASI dengan status gizi pada anak 12-24 bulan. Rata-rata durasi pemberian ASI 15 bulan, belum memenuhi rekomendasi global. Analisis tabulasi silang menguatkan adanya hubungan positif antara durasi pemberian ASI dan ASI eksklusif dengan pertumbuhan linier pada anak. ${ }^{21}$ 
Tabel 4 Hubungan Durasi Menyusui, Riwayat Penyakit Infeksi, Status Imunisasi, Sanitasi Lingkungan, besar keluarga dan Ketersediaan Pangan dengan Kejadian Stunting dan Underweight pada Balita di Desa Nyogan, 2019

\begin{tabular}{|c|c|c|c|c|c|c|c|c|c|c|c|c|c|c|c|c|}
\hline \multirow{3}{*}{ Variabel } & \multicolumn{4}{|c|}{ Stunting } & \multirow{2}{*}{\multicolumn{2}{|c|}{ Total }} & \multirow{3}{*}{$\begin{array}{l}\text { Prevalence Ratio } \\
\quad(95 \% \text { CI })\end{array}$} & \multirow{3}{*}{ P-value } & \multicolumn{4}{|c|}{ Underweight } & \multirow{2}{*}{\multicolumn{2}{|c|}{ Total }} & \multirow{3}{*}{$\begin{array}{l}\text { Prevalence Ratio } \\
\quad \text { (95\% CI) }\end{array}$} & \multirow{3}{*}{ P-value } \\
\hline & \multicolumn{2}{|c|}{ Ya } & \multicolumn{2}{|c|}{ Tidak } & & & & & \multicolumn{2}{|c|}{$\mathbf{Y a}$} & \multicolumn{2}{|c|}{ Tidak } & & & & \\
\hline & $\mathbf{N}$ & $\%$ & $\mathbf{n}$ & $\%$ & $\mathbf{n}$ & $\%$ & & & $\mathbf{n}$ & $\%$ & $\mathbf{n}$ & $\%$ & $\mathbf{n}$ & $\%$ & & \\
\hline \multicolumn{17}{|c|}{ Durasi Menyusui } \\
\hline$<24$ bulan & 14 & 63,6 & 8 & 36,4 & 22 & 100 & $2,92(1,26-6,76)$ & $0,011^{*}$ & 5 & 22,7 & 17 & 77,3 & 22 & 100 & $1,74(0,47-6,43)$ & 0,459 \\
\hline$\geq 24$ bulan & 5 & 21,7 & 18 & 78,3 & 23 & 100 & & & 3 & 13,0 & 20 & 87,0 & 23 & 100 & & \\
\hline \multicolumn{17}{|c|}{ Riwayat Penyakit Infeksi } \\
\hline Ada & 6 & 60,0 & 4 & 40,0 & 10 & 100 & $1,61(0,83-3,14)$ & 0,281 & 1 & 10,0 & 9 & 90,0 & 10 & 100 & $0,50(0,06-3,59)$ & 0,661 \\
\hline Tidak Ada & 13 & 37,1 & 22 & 62,9 & 35 & 100 & & & 7 & 20,0 & 28 & 80,0 & 35 & 100 & & \\
\hline \multicolumn{17}{|c|}{ Status Imunisasi } \\
\hline Tidak Lengkap & 11 & 57,9 & 8 & 42,1 & 19 & 100 & $1,88(0,94-3,76)$ & 0,130 & 5 & 26,3 & 14 & 73,3 & 19 & 100 & $2,28(0,61-8,39)$ & 0,253 \\
\hline Lengkap & 8 & 30,8 & 18 & 69,2 & 26 & 100 & & & 3 & 11,5 & 23 & 88,5 & 26 & 100 & & \\
\hline \multicolumn{17}{|c|}{ Sanitasi Lingkungan } \\
\hline Kurang Baik & 7 & 30,4 & 16 & 69,6 & 23 & 100 & $0,55(0,27-1,15)$ & 0,182 & 4 & 17,4 & 19 & 82,6 & 23 & 100 & $0,95(0,27-3,36)$ & 1,000 \\
\hline Baik & 12 & 54,5 & 10 & 45,5 & 22 & 100 & & & 4 & 18,2 & 18 & 81,8 & 22 & 100 & & \\
\hline \multicolumn{17}{|l|}{ Besar Keluarga } \\
\hline Besar & 3 & 60,0 & 2 & 40,0 & 5 & 100 & $1,50(0,66-3,37)$ & 0,636 & 3 & 60,0 & 2 & 40,0 & 5 & 100 & $4,80(1,61-14,25)$ & $0,033 *$ \\
\hline Kecil & 16 & 40,0 & 24 & 60,0 & 40 & 100 & & & 5 & 12,5 & 35 & 87,5 & 40 & 100 & & \\
\hline \multicolumn{17}{|c|}{ Ketersediaan Pangan } \\
\hline Kurang & 6 & 37,5 & 10 & 62,5 & 16 & 100 & $0,83(0,39-1,77)$ & 0,872 & 4 & 25,0 & 12 & 75,0 & 16 & 100 & $1,81(0,52-6,29)$ & 0,427 \\
\hline Cukup & 13 & 44,8 & 16 & 55,2 & 29 & 100 & & & 4 & 13,8 & 25 & 86,2 & 29 & 100 & & \\
\hline
\end{tabular}

Sumber : Data Primer Terolah, 2019 
Namun hasil penelitian ini tidak sejalan dengan penelitian Azriful dkk (2018) yang menunjukkan bahwa tidak ada hubungan antara pemberian ASI sampai dengan usia 2 tahun dengan kejadian stunting. Ini disebabkan karena pemberian makanan pendamping ASI (MP-ASI) tidak optimal terhadap balita. Hal ini sejalan dengan teori yang kemukakan oleh Robert dkk (2008 dikutip dalam Azriful dkk, 2018) yang menyatakan bahwa bahkan dengan penyusuan yang optimal, anakanak akan menjadi pendek jika mereka tidak mendapat kuantitas dan kualitas makanan pendamping yang cukup setelah usia 6 bulan. Sebagian besar kejadian stunting (dan wasting di luar situasi kelaparan) terjadi pada usia 2 tahun pertama kehidupan ketika anak-anak memiliki kebutuhan gizi yang tinggi dan ada keterbatasan dalam kualitas dan kuantitas makanan mereka, terutama setelah selesainya masa pemberian ASI eksklusif. $^{21}$

Air susu ibu hendaknya diberikan terus sampai anak berusia 2 tahun sebab ASI mengandung zat-zat gizi yang penting bagi anak, yang tidak terdapat dalam susu sapi. Lama pemberian ASI sebaiknya dihentikan ketika anak berusia 2 tahun, karena zat-zat yang terkandung didalam ASI sudah tidak dapat mencukupi kebutuhan anak. ${ }^{22}$ Pemerintah Indonesia juga sudah mengeluarkan kebijakan melalui Keputusan Menteri Kesehatan RI NO.450/MENKES/IV/2004 tentang pemberian ASI sampai 6 bulan dan dapat dilanjutkan sampai anak berusia 2 tahun. ${ }^{23}$

Durasi menyusui pada balita suku anak dalam di Desa Nyogan mendekati batas minimal pemberian ASI (24 bulan), namun masih belum mencukupi dan semestinya tetap diberikan hingga 24 bulan. Hal ini membuat pertumbuhan tinggi balita terhambat. Menghentikan lama pemberian ASI di usia kurang dari 2 tahun salah satunya dipengaruhi oleh aktivitas ibu diluar rumah untuk bekerja sehingga mengharuskan melakukan penghentian pemberian ASI yang digantikan oleh pemberian susu formula. Status gizi anak yang baik juga dipengaruhi oleh makanan pendamping ASI (MP-ASI) yang cukup dan pemberian ASI yang optimal sampai anak usia 2 tahun. Pemberian susu formula pada anak, dianggap praktis namun biasanya dapat menimbulkan anak obesitas atau gerak anak menjadi kurang aktif. Sebaiknya ibu diberikan pemahaman pentingnya memberikan ASI hingga dua tahun dan memotivasi keluarga untuk mendukung pemberian ASI pada anaknya, sehingga anak mendapatkan ASI hingga usia dua tahun dan dengan kuantitas serta kualitas MP ASI yang baik.

Penelitian ini belum dapat membuktikan adanya hubungan yang signifikan antara riwayat penyakit infeksi dengan kejadian stunting. Namun balita yang mempunyai riwayat penyakit infeksi memiliki risiko lebih besar untuk terkena stunting dibandingkan balita yang tidak punya riwayat penyakit infeksi. Demikian pula belum ditemukan hubungan signifikan antara status imunisasi dengan kejadian stunting, namun ada kecenderungan balita yang tidak mendapatkan imunisasi dasar lengkap punya risiko lebih besar untuk menderita stunting dibandingkan balita dengan imunisasi dasar lengkap.

Besar keluarga belum terbukti berhubungan dengan kejadian stunting, namun berdasarkan nilai asosiasi terlihat kecenderungan balita yang memiliki keluarga berukuran besar mempunyai risiko lebih tinggi untuk menjadi Stunting 
dibandingkan balita yang memiliki keluarga yang berukuran kecil. Belum ditemukannya bukti signifikan dari beberapa variabel tersebut dapat disebabkan oleh keterbatasan jumlah sampel yang tersedia pada penelitian ini, hal ini terlihat dari adanya sel dengan nilai observasi <5. Perlu dilakukan penelitian dengan jumlah sampel yang lebih besar dalam mengekplorasi lebih lanjut hubungan terhadap beberapa variabel tersebut pada penelitian selanjutnya.

Penelitian ini membuktikan adanya hubungan besar keluarga dengan kejadian underweight pada balita SAD. Ukuran keluarga yang besar meningkatkan risiko terjadinya balita underweight dibandingkan balita yang memiliki ukuran keluarga kecil. Jumlah anggota keluarga yang banyak berbanding lurus dengan kejadian gizi kurang yang tinggi di tingkat keluarga. Keluarga miskin akan memiliki beban yang lebih besar untuk memenuhi kebutuhan makanan jika jumlah anggota keluarga banyak. Besar keluarga mempengaruhi distribusi makanan dalam keluarga. Jika jumlah anggota keluarga bertambah tentunya porsi makan untuk tiap anggota keluarga berkurang (terlebih bila kemampuan ekonomi keluarga terbatas, seperti kemampuan keluarga SAD). Hal ini tentunya akan menyebabkan anggota keluarga yang masuk dalam kelompok umur balita akan menjadi lebih rentan terhadap gizi kurang. ${ }^{17}$

Hasil penelitian ini sejalan dengan penelitian yang dilakukan oleh Suyatman dkk di wilayah kerja Puskesmas Bandarharjo Kota Semarang pada tahun 2017 yang menunjukkan hasil bahwa ada hubungan yang signifikan antara jumlah anggota keluarga dengan gizi kurang pada balita, dimana balita yang memiliki jumlah anggota rumah tangga yang besar berisiko
12 kali lebih besar untuk mengalami gizi kurang dibandingkan dengan balita yang memiliki jumlah anggota rumah tangga yang kecil. ${ }^{17}$

Penelitian ini juga sejalan dengan penelitian Putri dkk di wilayah kerja Puskesmas Nanggalo Padang yang menunjukkan bahwa ada hubungan yang signifikan antara jumlah anggota rumah tangga dengan kejadian underweight $(\mathrm{p}=$ 0,008), dimana balita dengan jumlah anggota rumah tangga yang besar memiliki risiko lebih besar untukn mengalami underweight dibandingkan balita dengan jumlah anggota rumah tangga yang kecil. ${ }^{24}$ Namun penelitian ini tidak sejalan dengan penelitian Suhendri di Puskesmas Sepatan Kecamatan Sepatan Kabupaten Tangerang pada tahun 2009 yang menunjukkan bahwa tidak ada hubungan antara jumlah anggota rumah tangga dengan status gizi anak balita.

Jumlah anggota keluarga dapat mempengaruhi status gizi anak karena jumlah anggota rumah tangga yang besar tanpa diikuti oleh peningkatan jumlah pendapatan akan memperburuk status gizi keluarga secara keseluruhan. Karena jumlah anak yang banyak pada keluarga yang keadaan sosialnya cukup akan mengakibatkan berkurangnya perhatian dan kasih saying yang diterima oleh anak. $^{25}$

Jumlah anggota keluarga dan banyaknya balita dalam keluarga akan berpengaruh terhadap tingkat konsumsi makanan yaitu jumlah dan distribusi makanan dalam rumah tangga, dimana jumlah anggota keluarga yang besar tanpa diiringi dengan pendistribusian makanan yang baik akan menyebabkan anak balita dalam keluarga rentan menderita gizi kurang. Jumlah anggota keluarga merupakan indikator penting dalam 
pembagian makanan, semakin banyak jumlah anggota rumah tangga, akan semakin kecil pendistribusian makanan, hal ini menjadi rawan bila terjadi pada keluarga dengan sosial ekonomi terbatas, seperti kondisi keluarga Suku Anak Dalam yang mempunyai rata-rata pendapatan yang relatif rendah.

Sementara itu jumlah anak yang banyak pada keluarga meskipun keadaan ekonominya cukup akan mengakibatkan berkurangnya perhatian dan kasih sayang orang tua yang di terima anaknya, terutama jika jarak anak yang terlalu dekat. Hal ini dapat berakibat turunnya nafsu makan anak sehingga pemenuhan kebutuhan primer anak seperti konsumsi makanannya akan terganggu dan hal tersebut akan berdampak terhadap status gizi anaknya. Sebaiknya keluarga khususnya orang tua pada suku anak dalam lebih memperhatikan jarak kehamilan/kelahiran dengan menggunakann alat kontrasepsi atau mengikuti program keluarga berencana agar jumlah anggota keluarga tetap terjaga dalam kondisi kecil sehingga pendistribusian makanan dapat terbagi dan tercukupi kepada setiap anggota rumah tangga, yang bertujuan menurunkan risiko anak balita mengalami gizi kurang.

Hasil penelitian ini belum dapat menemukan bukti adanya asosiasi antara durasi menyusui, riwayat penyakit infeksi, status imunisasi, sanitasi lingkungan dan ketersediaan pangan dengan kejadian underweight pada balita. Namun terdapat kecenderungan bahwa balita dengan durasi menyusui < 24 bulan memiliki risiko lebih tinggi untuk mengalami underweight dibanding dengan balita dengan durasi menyusui $\geq 24$ bulan. Demikian pula ada kecenderungan balita yang tidak mendapatkan imunisasi dasar lengkap lebih besar risikonya untuk underweight dibandingkan balita yang mendapatkan imunisasi dasar lengkap. Juga balita dengan ketersediaan pangan yang kurang berisiko lebih besar untuk mengalami underweight dibandingkan balita dengan ketersediaan pangan cukup.

Pemerintah Indonesia telah meluncurkan "Gerakan Seribu Hari Pertama Kehidupan" yang dikenal sebagai 1000 HPK. Gerakan ini bertujuan mempercepat perbaikan gizi untuk memperbaiki kehidupan anak-anak Indonesia di masa mendatang. Gerakan ini melibatkan berbagai sektor dan pemangku kebijakan untuk bekerjasama menurunkan prevalensi stunting serta bentuk-bentuk kurang gizi lainnya di Indonesia. Intervensi pada 1000 HPK difokuskan pada 2 jenis intervensi, yaitu intervensi gizi spesifik dan intervensi gizi sensitif. Intervensi gizi spesifik merupakan rangkaian berbagai kegiatan yang cukup cost effective khususnya untuk mengatasi masalah gizi pendek, sedangkan intervensi gizi sensitif merupakan berbagai kegiatan program pembangunan yang memberi pengaruh pada status gizi masyarakat terutama kelompok 1000 HPK, seperti penanggulangan kemiskinan, pendidikan, gender, air bersih, sanitasi, serta kesehatan lingkungan. ${ }^{26}$

Sebagian besar dari 13 intervensi di bidang gizi yang terbukti paling cost effective sudah dilaksanakan di Indonesia, namun hasilnya tidak efektif. Hal ini terutama karena masalah gizi sementara ini dianggap sebagai tanggung jawab sektor kesehatan semata. Sesungguhnya hanya $30 \%$ masalah gizi yang bisa diselesaikan oleh sektor kesehatan, sedangkan $70 \%$ lainnya harus dikerjakan oleh sektor lainnya. Perbaikan dalam tumbuh kembang anak setelah masa gagal tumbuh 
awal masih bisa diintervensi untuk mencegah gagal tumbuh yang menjadi akut dan kronis, sehingga perlu penambahan program 1000 HPK plus untuk mencapai keberhasilan dari program yang telah dicanangkan pemerintah. Khususnya pada komunitas Adat terpencil seperti SAD, diperlukan intervensi spesifik sesuai dengan karakteristik komunitas ini yang memiliki keterbatasan ekonomi dan pengetahuan.

Penelitian ini memiliki beberapa keterbatasan diantaranya adalah rendahnya kekuatan penelitian (power of study) dikarenakan jumlah sampel yang ada masih kurang dari jumlah sampel minimal, kekuatan studi ini hanya 66,9\% sehingga dibutuhkan sampel yang lebih besar untuk membuktikan adanya hubungan dari beberapa variabel lainnya.

\section{KESIMPULAN DAN SARAN}

Proporsi stunting yang ditemukan $42,2 \%$ dan underweight $17,8 \%$ pada balita SAD di Desa Nyogan Kabupaten Muaro Jambi. Ada hubungan antara durasi menyusui dengan kejadian stunting dan besar keluarga dengan kejadian underweight.

Pemerintah perlu melakukan revitalisasi program seribu HPK dengan program seribu HPK plus. Sebaiknya ibu balita tetap memberikan ASI hingga anak berusia 24 bulan (2 tahun) untuk mengurangi risiko balita mengalami stunting dan keluarga SAD juga perlu mengikuti program keluarga berencana untuk menjaga jumlah anak tidak lebih dari 2 orang (norma keluarga kecil) agar mengurangi risiko anak mengalami underweight.

\section{DAFTAR PUSTAKA}

1. Kartikawati, P. R. F. 2011. Faktor yang mempengaruhi kejadian stunted growth pada anak balita di wilayah kerja puskesmas arjasa kabupaten jember. pp. 1-24.

2. Wiyogowati, C. 2012. Kejadian Stunting Pada Anak Berumur Dibawah Lima Tahun (0-59 Bulan) di Provinsi Papua Barat Tahun 2010 (Analisis Data Riskesdas 2010). Skripsi. Fakultas Kesehatan Masyarakat. Universitas Indonesia, Depok.

3. Rozali, N. A. 2016. Peranan Pendidikan, Pekerjaan Ibu dan Pendapatan Keluarga Terhadap Status Gizi Balita di Posyandu Rw 24 dan 08 Wilayah Kerja Puskesmas Nusukan Kota Surakarta. Naskah Publikasi. Fakultas Kedokteran. Universitas Muhammadiyah Surakarta.

4. Kemenkes, RI. 2018. Hasil Utama Riskesdas 2018. Jakarta: Departemen Kesehatan Republik Indonesia.

5. Movanita, Ambaranie Nadia Kemala. 2017. Lama Hidup Nomaden, Kini Suku Anak Dalam Punya Hunian Tetap. [online]. (diupdate 19 Februari 2017). https://nasional.kompas.com/read/2 017/02/19/10111631/lama.hidup.no maden.kini.suku.anak.dalam.punya. hunian.tetap. [diakses 21 Januari 2019]

6. Dinas Sosial Tenaga Kerja dan Transmigrasi. 2013. Profil Komunitas Adat Terpencil (KAT) dan Program Pemberdayaan KAT di Provinsi Jambi.

7. Kalsum, U., Halim, R. \& Fitri, A. 2018. Pola Perkawinan, Pola 
Konsumsi dan Status Gizi Balita Orang Rimba di Desa Sungai Terap dan Hajran. Jurnal Kesmas Jambi (JKMJ), 2(2), p. 87-96.

8. Azriful et al. 2018. Determinan Kejadian Stunting pada Balita Usia 24-59 Bulan di Kelurahan Rangas Kecamatan Banggae Kabupaten Majene. Al-Sihah: Public Health Science Journal, 10(2), pp. 192203.

9. Rahmad, A. H. AL \& Miko, A. 2016. Kajian Stunting Pada Anak Balita Berdasarkan Pola Asuh dan Pendapatan Keluarga di Kota Banda Aceh. Jurnal Kesmas Indonesia, 8(2), p. 63-79.

10. Maywita, E. 2018. Faktor Risiko Penyebab Terjadinya Stunting pada Balita Umur 12-59 Bulan di Kelurahan Kampung Baru Kec. Lubuk Begalung Tahun 2015. Jurnal Riset Hesti Medan, 3(1), p. 56-65.

11. Cahyono, F., Manongga, S. P, \& Picauly, I. 2016. Faktor Penentu Stunting Anak Balita Pada Berbagai Zona Ekosistem di Kabupaten Kupang. Jurnal Gizi Pangan, 11(1), pp. 9-18.

12. Masrin, Paratmanitya, Y. \& Aprilia, V. 2014. Ketahanan Pangan Rumah Tangga Berhubungan dengan Stunting pada Anak Usia 6-23 bulan. Jurnal Gizi dan Dietetik Indonesia, 2(3), p. 103-115.

13. Sari, D. K., Tamtomo, D. G. \& Anantayu, S. 2017. Hubungan Teknik , Frekuensi , Durasi Menyusui dan Asupan Energi dengan Berat Badan Bayi Usia 1-6 Bulan di Puskesmas Tasikmadu Kabupaten Karanganyar. pp. 1-13. doi: $\quad$ 10.20473/amnt.v1.i1.2017.1-
13.

14. Namangboling, A. D., Murti, B. \& Sulaeman, E. S. 2017. Hubungan Riwayat Penyakit Infeksi dan Pemberian ASI Eksklusif dengan Status Gizi Anak Usia 7-12 Bulan di Kecamatan Kelapa Lima Kota Kupang. Sari Pediatri, 19(2), p. 9196.

15. Novitasari, D. and Puruhita, N. 2012. Faktor-Faktor Risiko Kejadian Gizi Buruk pada Balita yang Dirawat di RSUP Dr. Kariadi Semarang. Jurnal Media Medika Muda.

16. Alamsyah, D., Mexitalia, M., \& Margawati, A. 2015. Beberapa Faktor Risiko Gizi Kurang dan Gizi Buruk Pada Balita 12-59 Bulan. Jurnal Vokasi Kesehatan, 1(5), p. 131-135.

17. Suyatman, B., Fatimah, S., \& D. 2017. Faktor Risiko Kejadian Gizi Kurang Pada Balita (Studi Kasus di Wilayah Kerja Puskesmas Bandarharjo Kota Semarang). Jurnal Kesehatan Masyarakat (eJournal), 5(4), p. 778-787.

18. Lemeshow et al. 1991. Sampel Size Determination in Health Studies a Practical Manual. Geneva : World Health Organization.

19. Dinas Kesehatan Provinsi Jambi. 2017. Pemantauan Status Gizi 2015-2017. Jambi.

20. Fitri, R. K., Fatimah, S. \& Rahfiludin, M.Z. 2017. Analisis Faktor-faktor yang Mempengaruhi Status Gizi Balita Suku Anak Dalam (SAD) (Studi di Wilayah Kerja Puskesmas Pematang Kabau Kecamatan Air Hitam Kabupaten Sarolangun Jambi). Jurnal Kesehatan Masyarakat, 5(4), p. 
752-758.

21. Susilowati et al. 2010. BreastFeeding Duration and Children's Nutritional Status at Age 12-24 Months. Paeditar Indoinesia, 50(1), p. 56-61.

22. Fitriana, N. \& Astuti, A. W. 2010. Hubungan lama pemberian asi dengan status gizi anak usia 6-24 bulan di posyandu biduri tempel sidomulyo bambanglipuro bantul yogyakarta tahun 2010.

23. Keputusan Menteri Kesehatan Republik Indonesia Nomor 1059/MENKES/SK/IX/2004. 2004. Tentang Pedoman Penyelenggaran Imunisasi. Kemenkes RI.

24. Putri, R. F., Sulastri, D. \& Lestari, Y. 2015. Faktor-Faktor yang Berhubungan dengan Status Gizi
Anak Balita di Wilayah Kerja Puskesmas Nanggalo Padang. Jurnal Kesehatan Andalas, 4(1), p. 254-261.

25. Suhendri, U. 2009. Faktor-Faktor yang Berhubungan dengan Status Gizi Anak Dibawah Lima tahun (BALITA) di Puskesmas Sepatan Kecamatan Sepatan Kabupaten Tangerang Tahun 2009. Skripsi. FKIK. Universitas Islam Negeri Syarif Hidayatullah, Jakarta.

26. BAPPENAS, RI. 2012. Pedoman Perencanaan Program Gerakan Sadar Gizi dalam Rangka Seribu Hari Pertama Kehidupan (1000 HPK). 1-8 